\title{
Matizando o discurso eurocêntrico sobre a interpretação constitucional na América Latina ${ }^{1}$
}

\author{
Andrés Botero Bernal ${ }^{2}$
}

Resumo: Este trabalho propõe matizar os discursos que estendem à América Latina, o passado constitucional europeu, a um ponto de inviabilizar o nosso passado em uma questão específica: a interpretação constitucional. Esse discurso eurocêntrico é fruto de um exercício de colonização da cultura jurídica latino-americana, que deve ser posto sob suspeita. Da mesma forma, destaca-se que existiu uma interpretação constitucional na América Latina durante o século XIX e que o historiador do direito deve dialogar com o constitucionalista dogmático para dar, a este último, elementos na construção da memória de sua disciplina, de tal maneira que este possa identificar as relações hegemônicas que se desenvolveram no seu campo de atuação. Então,

\begin{abstract}
This paper proposes to nuance speeches extending to Latin America about the European constitutional past, speeches that invisibilize our past in a very specific issue: constitutional interpretation. This Eurocentric discourse is the result of an exercise of colonization of Latin American legal culture that has to be put under suspicion. Similarly, this paper indicates that existed constitutional interpretation in Latin America during the nineteenth century, and proposes that the legal historian must dialogue with the constitutionalist dogmatic for to build the memory of this discipline, so that it can identify the hegemonic relations that have gestated in this juridical area. Then, during the discussions
\end{abstract}

1 Grande parte das informações aqui fornecidas sobre a história da aplicação judicial da Constituição são obtidas de: BOTERO BERNAL, Andrés. Haciendo memoria de la defensa judicial de la constitución. In: Pensamiento Jurídico: Universidad Nacional de Colombia, No. 20 (septiembre-diciembre de 2007); p. 91-101. A versão em espanhol deste texto foi apresentada no Segundo Simpósio Internacional sobre Jurisprudência, Campeche, México, 2009. Agradeço os comentários críticos e sugestões dos professores Carlos Petit (Universidade de Huelva), Ramón Narváez (Instituto de Investigações Jurisprudenciais da Suprema Corte da Nação do México) e Andrea Macía (Universidade Autônoma de Madrid).

2 Professor da Universidade de Medellín. Correio eletrônico: botero39@gmail.com.

* Tradutor: Francisco Codorniz. Mestre em Análise Econômica do Direito pela Universidade de Salamanca, Espanha. Advogado, inscrito na OAB/RS sob o n ${ }^{\circ}$ 65.363. Graduado em Ciências Jurídicas e Sociais pela PUC-RS. Correio eletrônico: francisco codorniz@hotmail.com. 
pela ocasião das reflexões sobre o bicentenário, é importante repensar as relações que o direito constitucional hispano-americano assumiu com a dogmática constitucional do primeiro mundo, assunto este que a história do direito pode aportar muito mais do que ela mesmo creia.

Palavras-chave: Colonialismo cultural. Cultura jurídica. Interpretação judicial. Constituição. on the Bicentennial, it is important to rethink the relations that the Hispanic American constitutional law has assumed within the constitutional dogmatics from first-world, for which the history of law can make far more than it thinks.

Keywords: Cultural colonialism. Legal culture. Judicial interpretation. Constitution.

\section{Introdução}

O presente texto analisa um discurso acadêmico que considera que a história da defesa judicial da constituição obedece a dois mitos fundacionais: Marbury versus Madison, de um lado, e Kelsen, com seus tribunais constitucionais, de outro. Com base nisso, concluise que o referido discurso reproduz as lógicas do colonialismo cultural e do pensamento hegemônico e que, se nada for feito, terminarão por invisibilizar definitivamente o rol que outras esferas culturais, como a latino-americana, tiveram em relação à defesa judicial da constituição.

Para realizar esta tarefa, o trabalho começa com a exposição de um caso concreto que põe em evidência o juiz como era um ator importante na defesa da constituição, muito antes dos tribunais constitucionais. Igualmente, para finalizar, o leitor será advertido sobre os perigos dos colonialismos culturais em matéria jurídica.

Este texto é resultado do projeto de pesquisa já concluído, A cultura jurídica na antioquia do século XIX, financiado pela Universidade de Medellín (Colômbia).

Agradeço os comentários críticos e sugestões dos professores Ramón Narváez (Instituto de Pesquisas Jurisprudenciais da Suprema Corte da Nação do México) e Andrea Macía (Universidade Autônoma de Madrid) aos quais dedico este trabalho, não somente pelo seu valor acadêmico mas, acima de tudo, pela sua amizade incondicional. 


\section{O caso do Cruz Muñoz}

Em 2 de Agosto de 1833, o Sr. Cruz Munoz queixou-se, perante a Justiça, contra o prefeito ordinário ${ }^{3}$ do pequeno povoado de Quirimara, Antioquia, Nova Granada, porque este mandou colocar aquele no cepo, que o prefeito tinha em casa, e só permitiu sua liberdade após 24 horas de tal punição. Cruz, habilmente instruído por quem lhe redigiu a queixa, ${ }^{4}$ alega que foi violado o seu direito constitucional à liberdade individual; que se violou o procedimento estabelecido no "Código Sagrado de Nova Granada" 5 em relação à forma de como deter uma pessoa (isto é, que foi detido por autoridade sem competência e ficou preso mais de 24 horas sem ser informado, por escrito, no prazo de 12 horas, sobre o motivo de sua prisão); que a casa do prefeito não é prisão constitucionalmente nem legalmente constituída e, finalmente, que o cepo não é sanção válida para o seu caso. ${ }^{6}$

De acordo com o auto de prisão que o próprio prefeito entregou a Cruz, após os fatos ocorridos, este último foi detido por 24 horas por desobedecer, em várias ocasiões, a autoridade local.

3 N.T: Prefeito Ordinário decorre da tradução de "Alcalde Ordinário". O termo ordinário neste caso não possui tradução na língua portuguesa. Trata-se de uma figura do direito colonial que sobreviveu algum tempo durante a república. Este era eleito pelo "Cabildo", cumulando funções administrativas e judiciais de primeira instância.

4 Vários arrazoados de Cruz são firmados por uma terceira pessoa (Pascacio Uribe) a rogo do próprio interessado. O mais provável é que esta pessoa tenha redigido os documentos em questão, assunto que seguirá sendo investigado, pois é importante para estabelecer a formação de Uribe, em seu sentido mais amplo.

5 Página 6r, Documento 6735, Ordinária, Queixa, Demandante Cruz Muñoz, Demandado Prefeito de Quirimara, 1833, Arquivo Judicial Histórico de Medellín (a seguir A. J. H. M.).

6 Basta dizer que, na imaginação do antioquenho não letrado, o "cabildo" (N.T.: esta palavra não possui significado na língua portuguesa. Trata-se do corpo utilizado pela Espanha para administrar as suas entidades locais, mas neste contexto significa o espaço físico onde o "cabildo" atua) e a prisão eram o mesmo espaço. Várias normativas - como a que alega Cruz a seu favor - na verdade, tentaram separar os dois espaços, com pouco sucesso. Mesmo na "célebre causa" do Aguacatal (1873), em um dos testemunhos deste processo, o negro Evaristo Galiano se refere ao Cabildo para designar a prisão. MUÑOZ, Francisco de Paula. El crimen del Aguacatal. Medellín: Imprenta del Estado por León F. Villaveces, 1874. Capítulo IX, Parte II. 
O Juiz de Direito, conhecendo a queixa de Cruz, determinou ao prefeito paroquial que informasse sobre as suas ações, alegando este que tem sido o costume do lugar proceder desta forma por delitos de pouca consideração; que se violou qualquer lei escrita não foi por temeridade, senão porque não sabe ler nem escrever e que não há qualquer pessoa no povoado a quem pudesse perguntar sobre leis. ${ }^{7}$

Referiu-se o juiz, expressamente, ao costume de prática jurídica local, que estava bem respaldado normativamente pelo Livro V, Título III das Leis das Índias, dedicada aos prefeitos ordinários. ${ }^{8}$ Algo semelhante é encontrado no Título I do Livro VII, dedicado aos "pesquisadores" e aos "jueces de comisión", ${ }^{10}$ especialmente a Lei 10, normas estas que ainda mantinham a sua validade por mandato expresso republicano ${ }^{11}$ no momento do incidente. Finalmente, o alegado pelo prefeito, sobre o costume do seu lugar não era um argumento débil, seguindo as "normas indianas" vigentes, mas algo distinto aconteceu quando irrompeu, no jargão jurídico hegemônico - isto é, dos juízes e assessores de Direito - a constituição como uma norma jurídica superior. Ou seja, o costume não se justifica só por normas positivas que o autorizam ou que o referem, isto também se dá através de seus pressupostos socioculturais, como uma prática que acaba prevalecendo como norma jurídica, porque se deixa de se cumprir, deixa de existir, isto é, que se o costume perde a sua eficácia

\footnotetext{
Página 4r, Documento 6735, 1833, A.J.H.M.

8 Entre as leis deste título se encontram várias remissões ao costume ou prática "judicial" no distrito de atuação do juiz; vejam-se as leis 14 (que prevê uma norma, mas se refere que não será aplicada se o costume local "tiver introduzido o contrário"), 16 (que remete a que se siga o preceituado no costume do lugar em relação a quem deve conhecer os conflitos entre espanhóis e índios), 19 (que ordena seguir o costume local no relativo à jurisdição do prefeito) e 22 (que indica para seguir o costume local sobre as horas e as datas das audiências dos prefeitos).

9 N.T: "Pesquisadores" são os juízes encarregados que investigam um crime ou delito.

10 N.T: Os "jueces de comisión” são os juízes que recebem algum encargo especial.

11 As normas espanholas seguiam sendo fonte jurídica, sempre e quando não chocassem com as republicanas, conforme estabeleceu, entre outras normas, a Constituição de Angostura de 1819, a Constituição de 1821, a Lei de 13 de Maio de 1825 e a Lei de 14 de Maio de 1834. Formalmente, a normativa espanhola foi definitivamente revogada mediante o artigo 15 da Lei n. 153 de 1887.
} 
e o parecer da sua obrigatoriedade, ele deixa de ser válido. Assim, o prefeito de Quirimara, ainda imerso na concepção jurídico-colonial, estava convencido da validade do costume que lhe permitiu prender Cruz em sua casa, enquanto esta era uma prática que se constituiu em seu entorno, que estava autorizada pelo Direito vigente e, além disso, que a considerava como obrigatória (opinio iuris). Porém, se está diante de um caso onde o costume repetido é considerado obrigatório pelo prefeito, perdeu sua validade, não por faltar de seus elementos constitutivos já vistos, mas pelo discurso hegemônico de juízes de Direito que, entre outras coisas, afirmavam a existência de certa hierarquia que faz com que o costume deva ser analisado à luz de outras normas (neste caso, constitucionais) e que, em virtude de tal confrontação, poderá perder seu caráter vinculativo.

$\mathrm{Na}$ verdade, os argumentos do prefeito não convenceram o juiz de Direito, que presumiu e não admitiu prova em contrário, sobre o conhecimento da constituição e da lei (em seu sentido mais amplo, abrigando aqui, inclusive, as recopilações espanholas), assim como o alfabetismo do funcionário que julga (lembre-se que as recopilações estabeleciam que somente alfabetos poderiam ser juízes), ${ }^{12}$ pelo que condenou em reparações e custas processuais o Prefeito paroquial julgado.

12 Trata-se do livro 5, título III, Lei 4, da Recopilação das Índias, que afirma que para ser Prefeito é necessário ser pessoa qualificada e alfabetizada. Não obstante, tal exigência não era requerida na Península, tal como nos informa Tapia: "Para ser prefeito ordinário é necessário ter vinte anos de idade, e não é preciso saber ler ou escrever, sempre que seja homem capaz" TAPIA, Eugenio de. Febrero novísimo, ó librería de jueces, abogados y escribanos, refundida, ordenada bajo nuevo método, y adicionada con un tratado del juicio criminal, y algunos otros. Valencia: Imprenta de Ildefonso Mompié, 1828. Volume I, p. 196.

É comum a demanda por via oral perante os tribunais locais, embora alguns autores consideravam que esta havia caído em desuso, o que é correto se olharmos para o processo desenvolvido perante os juízes de Direito do Antigo Regime como da república. Nesta imprecisão cai MONTERO AROCA, Juan. La ley de enjuiciamiento civil española de 1855: la consolidación del proceso común. In: GIULIANI, Alessandro e PICARDI, Nicola (a cura di). L'Educazione giuridica. VI-Modelli storici Della procedura continentale. Tomo II - Dall'ordo iudiciarius al codice di procedura. Napoli: Edizioni Scientifiche Italiane, 1994. p. 383 e 447 (nesta última, cita a Tapias como a fonte de tal apreciação). 


\section{Assim sentencia o juiz de Direito:}

Vistos: $1^{\circ}$ Considerando que José Caro, prefeito paroquial de Quirimara, prendeu em sua casa, em prisão de cepo, o Sr. Cruz Muñoz, por vinte e quatro horas, e que não the entregou o auto até estas vinte e quatro horas, conforme consta no próprio e de informação de nossos feitos: $2^{\circ}$ que com estes fatos violou os artigos $186^{13}$ e $190^{14}$ da Constituição, não dando dentro de doze horas a cédula ou ordem que expresse os motivos da detenção e reclusão, e realizando esta em sua própria casa e não em lugar conhecido como prisão, e no caso de não existir esta deveria efetuar a prisão na capital da paróquia, ou punir com multa, conforme prevista no artigo 154 e seguintes da Lei de 11 de maio 1825 . Por estas razões e para administrar a justiça em nome da República e pela autoridade da lei se reprova o procedimento do prefeito José Caro, que é condenado nas custas, danos e prejuízos que por este procedimento tenha causado ao querelante, e para o seu cumprimento taxe-se as custas incidentes em três pesos, sem incluir os selos, e quanto aos prejuízos se ouvirá o prefeito, que poderá prorrogar os encargos que não sejam correntes, ou que sejam excessivos, entregando-lhe uma cópia desta sentença para que tome ciência o $1^{\circ}$ prefeito paroquial da paróquia que pertence Quirimara, para que se satisfaçam os prejuízos remediados por esta sentença. Estanislao Gomez [Assinatura e rubrica]. O provê o Senhor Juiz de direito em vinte e oito de agosto de mil oitocentos e trinta e três. Trujillo [Meiaassinatura e rubrica] Escrivão. ${ }^{15}$

13 Artigo 186: No prazo de doze horas, no máximo, de verificada a prisão ou detenção de alguma pessoa, o juiz expedirá uma ordem firmada, na qual se expressem os motivos da prisão ou detenção, se deve ou não estar ou continuar incomunicável o preso; e a este será dada uma cópia. $\mathrm{O}$ juiz que não cumprir esta disposição, e o carcereiro que não reclamar a ordem, passadas doze horas, serão punidos como réus de detenção arbitrária. Nem um nem o outro poderão usar de mais motivos ou prisões do que são necessárias para a segurança do preso ou detido (fora do texto). URIBE VARGAS, Diego. Las constituciones de Colombia. Madrid: Ediciones Cultura Hispánica, 1977. Tomo II, 1977, Op. Cit., p. 821. O texto de Uribe diz "doze anos" em vez de "doze horas". Nós corrigimos este erro na transcrição.

14 Artigo 190: Ninguém será enviado para a prisão em lugares que não são públicos e legalmente reconhecidos como prisões. Idem, p. 821.

15 Tradução feita do espanhol da época. Páginas 7r-7v, Documento 6735, 1833, A. J. H. M. 
Finalmente, o juiz condenou o prefeito nas custas do processo (que incluía o pagamento do advogado de Cruz, aparentemente Pascasio Uribe Ochoa, uma vez que ele aparece assinando o pedido do demandante) e a reparar os prejuízos causados. Ao mesmo tempo, o juiz de Direito coagiu o prefeito e ratificou, em seus "vistos", que se verificou uma violação da Constituição, nos artigos 186 e 190, violação que era constitutiva da sanção imposta.

Neste caso, tomado de uma amostra aleatória, para o juiz de Direito as normas constitucionais eram argumento jurídico válido e, portanto, condenou o prefeito. Mas, para conseguir isso, o juiz de Direito teve que se voltar a uma interpretação da constituição (pois se acredita que esta aplicação é mediada por uma interpretação), ${ }^{16}$ não somente pelas normas constitucionais invocadas por Cruz, senão também por aquelas norma vigentes que tratavam do Poder de Polícia - em um sentido contemporâneo - das autoridades locais, assim como da presunção de legalidade do costume local. Não há qualquer registro dos juízos interpretativos realizados pelo juiz. Somente existe este pequeno resumo das investigações jurídicas judiciais nos "vistos"; mas, apesar deste silêncio, é evidente que o juiz de Direito privilegiou a constituição ao costume, e interpretou a primeira para aplicá-la a um caso concreto. Sem embargo, o que é surpreendente neste caso é a data: 1833. Bem que poderia, o sábio leitor, determinar a data pelo contexto do caso mas, se não fosse por essas circunstâncias contextuais, poderia tratar-se de um "recurso de amparo" apresentado na contemporaneidade.

\section{A história do judicial review (defensa judicial da constituição) feita pela ciência jurídica}

No entanto, em setembro de 2006, em Medellín, em uma reunião com renomados colegas constitucionalistas e jus-filósofos espanhóis,

\footnotetext{
16 Este tema poderia dar muito mais do que falar. Sem embargo, aqui se quer apenas recordar como a suposta aplicação mecânica da lei, sem interpretação, foi aceita por muitos como um "mito jurídico" da modernidade. Isto leva, ademais, a uma crítica generalizada da filosofia do Direito à proposta dworkiana de um juiz Hércules que encontra a única decisão jurídica correta para cada caso que lhe seja posto.
} 
em uma atitude muito amável - mas própria de exercícios que podem ser denominados de neocolonialismo jurídico ${ }^{17}$ - explicaram, a partir de dualidades irredutíveis (pedagogicamente muito boas, mas completamente distanciadas da realidade histórica), as diferenças entre os modelos constitucionais: de um lado, o Estado liberal (legicentrista, positivista, do século XIX) e do outro, o Estado constitucional (constitucional-centrista, não positivista, contemporâneo). De acordo com este discurso, assistido com muita atenção pela plateia, a Constituição colombiana de 1991 se insere no segundo modelo, sendo assim um "filho legítimo" da tradição constitucionalista europeia do pós-guerra, em especial da constituição espanhola. Com base nesta dicotomia, que se encontra também na maioria dos textos constitucionais europeus, explicaram-se as principais características das constituições e das concepções que se utilizam para observá-las ao longo da modernidade: ${ }^{18}$

17 Dois esclarecimentos: I) Estes exercícios do "colonialismo" são alheios, por vezes, à vontade dos agentes colonizadores, o que supõe pensar também no papel dos colonizados nestes mesmos exercícios. Inclusive, em vários casos, é possível que a colonização se deva mais ao papel dos colonizados que ao dos colonizadores. II) Alguns colegas preferem o uso de "pós-colonialismo", outros de "colonialismo", há aqueles que sugerem o uso de "pensamento hegemônico", também "colonialismo cultural", etc. Diante de tal variedade de significantes para o mesmo fenômeno deixa-se nas mãos do leitor o uso do termo que considere mais apropriado.

18 Existem muitos textos que partem do uso de dicotomias para explicar o modelo constitucional atual. Por exemplo: Aguiló Regla, Josep. Sobre derecho y argumentación. Palma de Mallorca: Lleonard Muntaner, 2009. p. 16-26. Este autor, através de dez conjuntos de oposições, diferencia o antigo modelo de "império da lei" do atual "Estado constitucional" ou "pós-positivista". Igualmente procede este mesmo autor, em outro texto, ao propor quatro pares de concepções sobre a constituição, que acaba por simplificar em dois (de um lado a concepção constitucional mecânico-procedimental-política como fonte das fontes do Direito, e do outro a concepção normativo-substantivista-jurídica como fonte do Direito), ainda que o mesmo qualifique esta dicotomia ao lembrar que não é absoluta, senão que versa sobre "pesos e acentos". AGUILÓ REGLA, Josep. Cuatro pares de concepciones opuestas de la Constitución. In: AGUILÓ REGLA, Josep; ATIENZA, Manuel y RUIZ MANERO, Juan. Fragmentos para una teoría de la Constitución. Madrid: Iustel, 2007. p. 21-62. Algo semelhante acontece com Zagrebelsky que parte da oposição entre um velho "direito por regras" (ou "tipicamente positivista") de um vigente "direito por princípios" (que atua como se fosse um direito natural). ZAGREBELSKY, Gustavo. El derecho dúctil: ley, derechos, justicia. Trad. Marina Gascón. Madrid: Trotta, 1999. p. 109-130. Também Alexy, que distingue dois sistemas, o "legalista" (próprio, diz 
1. As constituições do século XIX e de princípios do século XX continham programas políticos (sendo, então, fonte política e não jurídica da lei), as contemporâneas apresentam normas jurídicas (como fontes de Direito no sentido estrito).

2. As constituições do século XIX e de princípios do século XX não estabeleciam hierarquias perante a lei e o seu sistema de reforma não era mais difícil do que o da lei, as contemporâneas sim.

3. As constituições do século XIX e de princípios do século XX não estabeleciam sistemas de defesa judicial, as contemporâneas sim.

4. A justiça constitucional contemporânea se deve ao constitucionalismo europeu do pós-guerra que, por sua vez, possui raízes em dois grandes pilares: Kelsen e os seus tribunais constitucionais, por um lado, e a tradição estadunidense que começou com o famoso caso de Madison v. Marbury, por outro. Portanto, a defesa judicial da Constituição Latino-Americana se limita a um transplante das duas tradições jurídicas "maiores" sobre o tema: a tradição estadunidense de sistema difuso com decisões judiciais de efeito inter-partes, e a tradição européia de sistema concentrado, com decisões de caráter político dos tribunais constitucionais (políticos também para Kelsen), com efeitos erga omnes.

Em suma, o que foi dito e o que não foi dito acabou por gerar um ar terrível na plateia: o século XIX foi um desperdício de tempo para o pensamento jurídico ocidental (incluindo a Hispano-América) e que, graças à evolução constitucional do primeiro mundo durante a segunda metade do século XX, houve uma revolução constitucional que, em virtude da capacidade de expansão de "boas" ideias, chegou à humilde América Latina, o que bem justifica citar os acadêmicos europeus para que expliquem aos latino-americanos, com termos básicos e com dicotomias fáceis de memorizar acriticamente, este processo de "transplante jurídico". ${ }^{19}$

ele, dos sistemas do século XIX e de princípios do século XX), do "constitucionalista" (na época contemporânea). ALEXY, Robert. El concepto y la validez del derecho. Trad. Jorge M. Seña. Barcelona: Gedisa, 1994. p. 159-177. Enfim, estes conjuntos de oposições não podem ser aplicados, sem mais, à tradição constitucional latino-americana.

19 Conceito de: WATSON, Alan. Legal transplants: An approach to comparative law. Edinburgh: Scottish Acad. Press, 1974. Nome, no mínimo, criticável, pois dá a entender que o processo se limita a uma ação unilateral a partir da parte hegemônica na relação centro-periferia. Poderia ser melhor o termo "recepção criativa"; isto é, reconhecer 
Diante de tais afirmações, se poderia replicar com argumentos históricos, uma questão que suporia questionar este esquema de dualidades e dicotomias que, por ser tão repetido na formação dos juristas, já se tem como uma verdade (um assunto que, por sinal, permitiria uma análise do neocolonialismo jurídico existente, o que suporia colocar sob suspeita não somente o papel desempenhado pelo "centro" mas, sobretudo, o da "periferia"). Então, seria possível que este sistema memorizado não fosse certo? Certamente é possível duvidar de sua certeza.

Não se poderia falar neste texto sobre o que aconteceu com o constitucionalismo europeu, mas, no que diz respeito ao constitucionalismo latino-americano, pode-se dizer, com certeza, que muitas de nossas constituições do século XIX foram normas jurídicas (sem remover, isso sim, as suas implicações políticas), que estabeleciam certos sistemas hierárquicos perante a lei, que foram defendidas de diversas e várias maneiras pelos juízes e que, aliás, eram em certa medida rígidas.

\section{A constituição e os juízes do século XIX}

Um bom exemplo do anterior é o caso do Sr. Cruz, o qual constituía parte de uma amostra, escolhida aleatoriamente, de 190 processos judiciais transcritos, correspondentes ao período de 18121899, na província de Antioquia (Colômbia). Nessa amostra, verificouse que em 10 processos é citada, explicitamente, em algumas de suas partes, a constituição. Mas isso não era algo isolado da Antioquia, senão que, dialogando com colegas jus-historiadores, casos semelhantes ocorreram também em outras comarcas judiciais e em outros países latino-americanos durante o mesmo período. Em outras palavras, não é difícil encontrar decisões judiciais do século XIX que tenham citado diretamente a constituição, seja para limitar os poderes do Estado, seja

\footnotetext{
que, em matéria jurídica, pelo menos, não se copia sem mais, senão que se reconstrói internamente e externamente o "modelo", o que explica, de um lado, as diferenças que se suscitam entre o "enviado e/ou tomado" com o "recebido e/ou copiado" e, do outro, as diferenças existentes entre os diversos sistemas que "bebem" das mesmas fontes.
} 
para executar os seus mandatos de maneira imediata. ${ }^{20}$ Claro está que essas citações podem ter muitas origens distintas, tal como a busca por critérios de autoridade por parte do juiz, da época liberal, para fundamentar a sentença. Pode, também, tratar-se de um Estado legal em projeto constitucional e, portanto, o juiz citava a constituição como forma de implantar o legalismo-estatismo. Inclusive, essas citações comprometem o investigador na busca de significados além dos artifícios dogmáticos do presente: o que entender por "constituição" e por "lei" no século XIX?21 No entanto, essas citações de ordens ou pedidos sugerem, pelo menos, uma vivência jurídica da constituição, ${ }^{22}$ que o dogmático constitucionalista não pode ignorar.

Como prova, mas sem pretender ser exaustivo, tais despachos e petições foram: ${ }^{23}$ 1) Petição dos cidadãos Miguel e Rafael Fernández para que se proveja o pagamento de alguns créditos, e o Ministério Público recomendou, sempre, e quando não se viole com isto a constituição vigente (Arquivo Judicial Histórico de Medellín, documento n. 3.300, 1815). 2) Petição de Juan de Dios Uribe para que fosse eximido de um emprego consultivo (Arquivo Judicial Histórico de Medellín, documento 361, 1825).

${ }^{20}$ Veja RESTREPO PIEDRAHITA, Carlos (Comp.). Control de constitucionalidad: Colombia y República de Nueva Granada, 1821-1860. Bogotá: Universidad Externado de Colombia, 2006. Este texto incorpora diversos atos jurídicos e decisões judiciais que aplicaram diretamente as constituições neogranadinas do século XIX, para sugerir a existência de um controle de constitucionalidade desde essa época.

${ }^{21}$ Os detalhes contidos nestas linhas surgiram pela pertinência dos comentários críticos do professor Carlos Petit.

22 "A Constituição vive em quanto se aplica pelos juízes", COUTURE, Eduardo J. Estudios de derecho procesal civil. Tomo I: La constitución y el proceso civil. 2. ed. Buenos Aires: Depalma, 1978, p. 95. Isto remete à clássica distinção entre "ter uma constituição" e "estar em constituição" (VERDÚ, Pablo Lucas. Tener y estar en Constitución. In: Anales de la Real Academia de Ciencias Morales y Políticas, n. 85 (2008); p. 322-334). Esta distinção é importante porque, como disse Aguiló, é possível "estar em constituição" sem "ter uma constituição". AGUILÓ, Josep. Sobre la constitución del estado constitucional. In: Doxa, 24 (2001); p. 445. Em consequência, urge estudar como viveu a constituição (por exemplo, entre os juízes) tanto (ou mais) que estudar o que disse uma constituição formal.

${ }^{23}$ Em BOTERO, Haciendo memoria..., op. cit., apareceu esta mesma lista, mas com alguns erros em relação às fontes do arquivo de que foram tomadas. Vale esta publicação para corrigir este erro involuntário. 
Naquele, a prefeitura informou ao senhor governador e comandante militar sobre a eleição dos prefeitos ordinários conforme a constituição e as leis, ao interpretar um silêncio constitucional sobre a quantidade de bens que deveriam ter os escolhidos para ocupar tal encargo. 3) Processo ordinário de queixa do Sr. Cruz Muñoz contra o prefeito de Quirimara, 1833, por "ter violado na minha pessoa a Constituição do Estado" ao privá-lo da liberdade no cepo da casa do prefeito (Arquivo Judicial Histórico de Medellín, sentença n. 6.735, 1833). 4) Arrazoado do "abogado de pobres" (defensor público) em um caso de contrabando em que assinalou que, ao se tomar o juramento de seus clientes, foi violada a constituição, pelo que pediu que esses fossem aliviados de suas obrigações; e a sentença deste processo, em que o juiz observou que a apreensão que se fez dos cultivos de tabaco dos réus não era compatível com a constituição (Arquivo Judicial Histórico de Medellín, documento n. 2.341, 1833). 5) Incidente civil entre "Francisco A. Gónima e Pablo Pizano, José Maria Uribe Restrepo, José Antonio Gaviria e Manuel José Manuel Tirado, fiadores de Manuel Latorre, que foi interventor da tesouraria da Fazenda da província, juiz de Direito da Fazenda e desta comarca" (1845), onde uma das partes fundamentou sua alegação no sentido de que a sentença de primeira instância violou o estipulado pelo artigo 158, além de outras citações recorrentes à constituição em outras questões de Direito (Arquivo Judicial Histórico de Medellín, documento n. 1.473, 1845). 6) Ação de responsabilidade contra José María Escobar, porque "como juiz da comarca de Sopetrán atrasou um expediente", ao qual foi anexada uma cópia da escritura de posse que, por sua vez, certificou o "juramento constitucional de desempenhar bem e fielmente seu cargo" requerido para a posse de juiz e secretário (Arquivo Judicial Histórico de Medellín, documento n. 1.831, 1860). 7) A "Instrução promovida por Miguel Jaramillo relativa à ação que tramita contra Joaquina Upegui, que se destina a declarar a executoriedade da sentença de primeira instância" (Arquivo Judicial Histórico de Medellín, documento n. 94, 1864) onde, tanto uma das partes, como o próprio Tribunal, citam a constituição em seus fundamentos de Direito, especialmente para determinar a constitucionalidade, ou não, da retroatividade de uma lei. 8) Em um processo pelo crime de furto (Arquivo Judicial Histórico de Medellín, documento n. 2.073, 1870), os testemunhos e o interrogatório começam com fórmulas em que se refere o respeito pelos mandatos constitucionais no momento de colher essas provas. 9) Arrazoado 
do promotor que investiga o crime do Aguacatal (1873) ${ }^{24}$ sobre a forma de interpretar a norma constitucional desse tempo, que proibiu uma pena pessoal de mais de dez anos. 10) Instrução para averiguar se o diretor do presídio e outros funcionários desse estabelecimento cometeram algum delito, iniciada em 5 de janeiro de 1882 pela prefeitura do departamento, onde foi citado e aplicado diretamente o inciso $4^{\circ}$, artigo $3^{\circ}$ do ato legislativo reformatório da Constituição do Estado, na qual se adverte a todos os acusados sobre seus direitos constitucionais e se acatam as formalidades constitucionais para a declaração (Arquivo Judicial Histórico de Medellín, documento n. 4.815 (2.790), 1882).

\section{Outras coisas ademais do Marbury v. Madison e do Kelsen}

Igualmente, a defesa judicial da constituição não é um assunto que se deva exclusivamente à dualidade Marbury v. Madison, de um lado, e a Kelsen e o constitucionalismo europeu do pós-guerra, de outro. Podese referir agora, mais precisamente, que sobre o tema relativo ao controle judicial da constituição, tem razão Prakash, ${ }^{25}$ ao apontar que os debates mais famosos acerca da supremacia constitucional são feitos pelos juízes federais estadunidenses, com casos reconhecidos como Marbury v. Madison, Dred Scott v. Sandford (que merece um estudo apartado, por ser um caso de fronteiriço entre diversas tendências na judicial review), ${ }^{26}$ Brown v. Maryland, e Roe v. Wade, entre outros. Entetanto, Marbury não foi o primeiro caso judicial de supremacia constitucional, porque já existia um certo ambiente institucional (e não apenas judicial) em favor da medida. Poder-se-ia citar alguns casos, como o debate sobre a constitucionalidade da Decisão de 1789 sobre a criação de um Departament of Foreing Affairs (Departamento dos assuntos exteriores), as legislaturas de Virgínia e de Kentucky que solucionaram a inconstitucionalidade da Alien and Sedition Acts, e a contenda surgida em The Federalist em torno do sistema de freios

\footnotetext{
24 MUÑOZ, El crimen, op. cit.

25 PRAKASH, Saikrishna. New Light on the decision of 1789. In: Cornell Law Review, Vol. 91, July 2006, n. 5; p. 1022-1023.

26 SCHWARTZ, Bernard. A history of the Supreme Court. New York - Oxford: Oxford University Press, 1993, p. 105-125.
} 
e contrapesos como um refinamento do modelo de separação de poderes, a fim de evitar que um poder se sobreponha aos outros ou que dois poderes se unam contra o terceiro. Por seu lado, Treanor ${ }^{27}$ analisa 38 casos prévios à decisão de 1803, que marcaram um forte precedente de controle judicial da Constituição, concluindo "that judicial review was dramatically better established in the years before Marbury than previously recognized"28 ("que o judicial review foi dramaticamente mais bem estabelecido nos anos antes do Marbury que o que previamente se reconhece"). Inclusive, Pereira e Ahumada, que apontam que Marbury iniciou a judicial review nos Estados Unidos, reconhecem a existência de circunstâncias precedentes que marcariam, inevitavelmente, o caminho tomado por Marshall em 1803 e continuado durante todos esses anos naquele país. ${ }^{29}$ Acrescente-se que as declarações judiciais estadunidenses de inconstitucionalidade não se limitam a efeitos interpartes, pois são possíveis pro futuro, caso Linkletter v. Walker (381, U.S. 518, 1965) e U.S. v. Johnson (457 U.S. 537, 1982), para mencionar apenas dois casos.

Com respeito ao interregno do século XIX, vale recordar que a jurisprudência estadunidense avançou consideravelmente no tocante a exercícios de interpretação direta da Constituição com implicações limitativas à atividade estatal, assunto que analisa Frickey ${ }^{30}$ para o caso de nações indígenas.

Já no que se refere à realidade hispano-americana, deve notar-se que não foi pouco o que se fez neste sentido, embora não se trate de um

27 TREANOR, William Michael. Judicial review before Marbury. In: Stanford Law Review, Vol. 58, Number 2, November 2005; p. 455-562.

28 Ibid., p. 457.

29 PEREIRA MENAUT, Antonio Carlos. Lecciones de teoría constitucional. 2. ed. Madrid: Editorial Revista de Derecho Privado, 1987, p. 245-246. AHUMADA RUÍZ, María Ángeles. Marbury Versus Madison, Doscientos años (y más) después. In: Fundamentos, n. 4, 2006, p. 112 et seq. Outros estudos sobre os antecedentes do caso Marbury: FERNÁNDEZ SEGADO, Francisco. Evolución histórica y modelos de control de constitucionalidad. In: GARCÍA BELAUNDE, D.; FERNÁNDEZ SEGADO, F. (Coord.). La jurisdicción constitucional en Iberoamérica. Madrid: Dykinson, 1997.

30 FRICKEY, Philip P. (Native)American Exceptionalism in Federal Public Law. In: Harvard Law Review, v. 199, December 2005, n. 2, p. 431-490. 
controle judicial no sentido contemporâneo do termo, mas sim algo de que se deve fazer "memória". 31

Em primeiro lugar, deve-se referir sobre as fontes doutrinais que serviram de apoio ao processo constitucional; em especial, as teorias da "fortaleza". Acontece que, durante princípios do século XIX, discutiuse, especialmente na Hispano-América, se a constituição regia sobre a "fortaleza" que protege o país contra o inimigo, ou se rege sobre todas as ações do Estado, inclusive quando este sai de sua fortaleza para repelir o invasor. A primeira das teorias afirmava que, enquanto o Estado estiver na defensiva ou em paz - isto é, quando a nação está guarnecida na fortaleza - a constituição vige plenamente, mas uma vez que o Estado sai da fortaleza para lutar contra o inimigo - isto é, em um momento de exceção -, esta deixa de regê-lo ou, pelo menos, não o rege nos pontos críticos, pelo que o Estado é livre até que a ordem seja restabelecida, com o que regressa à sua disposição constitucional originária. Obviamente, com esta teoria, a constituição está a um passo de consagrar-se somente como mandato político, e não como um imperativo jurídico sobre o governo (em sentido amplo), posto que bastaria uma exceção nas circunstâncias nacionais, decretada pelo próprio governo, para que a constituição fique sem efeito: ou seja, seria um simples programa político. Neste sentido, foi um constitucionalista com grande influência no meio americano, Benjamin Constant ${ }^{32}$ que, em seus estudos sobre a suspensão e violação da constituição, critica a concepção da constituição como fortaleza, isto é, critica aqueles que acreditam que esta não foi feita para abrigar

31 Existem vários trabalhos constitucionalistas sobre o caso europeu, que indagam por instituições, normativas, debates, etc., nos quais se poderia deduzir algo interessante para uma memória da justiça constitucional, como o jury constitutionnel de Sieyès ou violações à Constituição de Cádiz. LORENTE SARIÑENA, Marta. Las infracciones a la constitución de 1812. Madrid: Centro de Estudios Constitucionales, 1988. Veja-se a síntese feita por FERNÁNDEZ, Evolución histórica, op. cit.; DIETZE, Gottfried. Judicial review in Europe. In: Michigan Law Review, v. 55, February 1957, n. 4; p. 539 et seq.

Sobre a importância do conceito "memória" na história do direito, ver: PETIT, Carlos. De la historia a la memoria. A propósito de una reciente obra de historia universitaria. In: Cuadernos del Instituto Antonio de Nebrija de Estudios sobre la Universidad, n. 8 (2005); p. 237-279.

32 Entre outros: CONSTANT, Benjamin. Curso de politica constitucional. Trad. D. J. C. Pages. Paris: Librería de Rosa, 1825. Segundo Tomo, p. 223-246. 
o inimigo e, portanto, que quando está bloqueada, a guarnição pode sair para dispersar aos que a sitiam. Portanto, todo governo constitucional (em seu sentido mais amplo) sempre deve acatar a constituição (tanto de governos republicanos como de monarquias constitucionais). No entanto, o influente francês não resiste em deixar uma exceção: Se for antiga, esta democracia pode "sair" da Constituição para defender o sistema político, em momentos profundamente excepcionais, mas um sistema jovem não poderia violá-la em nenhum momento.

Em segundo lugar, deve-se mencionar algo sobre o processo de amparo mexicano, especialmente como foi estabelecido na Constituição do Estado de Yucatán de 1841 (bem como a reforma constitucional federal de 1847, e as constituições de 1857 e 1917), amplamente analisados por vários constitucionalistas, ${ }^{33}$ por seu papel no desenvolvimento de uma aplicação direta de certos direitos constitucionais a uma supremacia constitucional. ${ }^{34}$

Outro ponto que gostaria de destacar e que não poderá ser passado por cima, entre os casos mais renomados, são os seguintes: a ação popular de inconstitucionalidade dos atos dos legisladores provinciais o artigo 113 , inciso $8^{\circ}$ da Constituição venezuelana de 1858; artigo 50

33 Incluo aqueles que afirmam taxativamente que esta instituição remonta à colônia, em especial pelos recursos de força, súplica e de notória injustiça CID SEBASTIÁN, Elia. Antecedentes del juicio de amparo. De la Real Audiencia a la Suprema Corte de Justicia de la Nación. In: SUPREMA CORTE DE JUSTICIA DE LA NACIÓN. Historia de la Justicia en México, siglos XIX y XX. Tomo I. México: Suprema Corte de Justicia de la Nación, 2005, p. 89-116. Também aos que a consideram como resultado da influência anglo-americana, castelhana, indiana e francesa, que foi forjada na dialética entre federalistas e centralistas mexicanos ABREU Y ABREU, Juan Carlos. La justicia constitucional a dos fuegos: federalistas contra centralistas. In: SUPREMA CORTE DE JUSTICIA DE LA NACIÓN. Historia de la Justicia en México, siglos XIX y XX. Tomo I. México: Suprema Corte de Justicia de la Nación, 2005. p. 3-21.

34 FIX-ZAMUDIO, Héctor y VALENCIA CARMONA, Salvador. Derecho constitucional mexicano y comparado. México: Porrúa y UNAM, 1999. p. 797-802. EDER, Phanor J. Judicial review in Latin American. In: Ohio State Law Journal, 1960; p. 570-615. SOBERANES, José Luis. Notas acerca del control de la constitucionalidad de las leyes. In: Estudios jurídicos en homenaje al profesor Santa Cruz Teijeiro. Valencia: Universidad de Valencia, 1974. Tomo 2, p. 420-421. NARVÁEZ HERNÁNDEZ, José Ramón. Historia social de la defensa de los derechos en México: El origen del juicio de amparo en la península yucateca. México: Suprema Corte de Justicia de la Nación, 2007. 
da Constituição da Colômbia (da Confederação Granadina) de $1858^{35}$ - e logo sobre todos os atos jurídicos estatais - artigo 110 , inciso $8^{\circ}$ da Constituição venezuelana de 1893 e artigo 95, inciso $10^{\circ}$ da Constituição venezuelana de 1904 -, bem como a aplicação preferencial da Constituição sobre a lei, nos termos do artigo $5^{\circ}$ da Lei colombiana 57 de 1887 (esta norma foi alterada pela Lei n. 153 de 1887 , artigo $6^{\circ}$, que determinava a presunção de constitucionalidade de toda lei promulgada durante a Constituição colombiana de 1886 , sendo que a supremacia constitucional com controle judicial, que se referia à Lei n. 53 de 1887, ficava limitada, na prática, às leis anteriores à Constituição de 1886) e o artigo $20^{\circ}$ do Código de Processo Civil venezuelano de 1897;36 a ação pública de inconstitucionalidade consagrada primeiramente na lei segunda de $1904^{37}$

35 Assim diz: "Cabe à Corte Suprema suspender a execução dos atos das Legislaturas dos Estados, quando sejam contrárias à constituição ou às leis da Confederação; dando conta da suspensão ao Senado, para que este decida definitivamente sobre a validade ou nulidade desses atos".

Igualmente, devem mencionar-se as possibilidades da suspensão dos atos jurídicos quando eles violavam a constituição. Por exemplo, os artigos 14, 59 e 87 da Lei de 19 de maio de 1834 permite ao governador, aos chefes políticos e, parcialmente, aos alcaides suspender os acordos municipais se os acordos violarem a constituição ou a lei. Também o artigo 49 da Lei de 3 de junho de 1848 que permite ao governador suspender atos da câmara provincial do cabildo ou de qualquer outra autoridade municipal que são contrários à constituição ou à lei. A Lei n. 149 de 1888 dizia que os governadores poderiam suspender acordos municipais contrários à constituição ou à lei, porém em nesse caso o mais importante era que o juiz de circuito decidia em primeira instância e logo o tribunal para decisão definitiva.

36 BREWER-CARÍAS, Allan R. El sistema mixto o integral de control de constitucionalidad en Colombia y Venezuela. In: AA.VV. Anuario de derecho constitucional latinoamericano. Medellín: Fundación Konrad Adenauer, CIEDLA, Asociación Venezolana de derecho constitucional, Asociación costarricense de derecho constitucional y Diké, 1996, p. 163-243. BREWER-CARÍAS, Allan R. La jurisdicción constitucional en América Latina. In: GARCÍA BELAUNDE, D.; FERNÁNDEZ SEGADO, F. (Coord.). La jurisdicción constitucional en Iberoamérica. Madrid: Dykinson, 1997, p. 125-135. AYALA CORAO, Carlos M. La jurisdicción constitucional en Venezuela. In: GARCÍA BELAUNDE, D.; FERNÁNDEZ SEGADO, F. (Coord.). La jurisdicción constitucional en Iberoamérica. Madrid: Dykinson, 1997, p. 933-936. AYALA CORAO, Carlos M. Origen y evolución del control constitucional en Venezuela. In: AA.VV. Anuario de derecho constitucional latinoamericano. Medellín: Fundación Konrad Adenauer, CIEDLA, Asociación Venezolana de derecho constitucional, Asociación costarricense de derecho constitucional y Diké, 1996, p. 247-284.

37 Cf. Diário Oficial 12.148 de 20 de agosto de 1904. 
e na reforma constitucional de 1910, através da qual se outorga à Suprema Corte de Justiça da Colômbia, a faculdade de excluir do ordenamento jurídico as leis que contrariem a constituição, assunto que alguns juristas colombianos analisam com grande efusividade sentimental, e a ação de inaplicabilidade de uma norma inconstitucional, assim como a nulidade de atos jurídicos municipais contrários à constituição, estabelecida no Panamá, em 1917, entre os casos mais renomados.

Em relação ao contexto da obra de Kelsen, deve-se notar que ele, ainda que tenha desempenhado um papel crucial como organicista, não se pode afirmar que não houvesse, na mesma época, outras melodias que, com um ritmo similar, mas de menor volume, retumbaram no cenário. Lembremos, por exemplo, como o próprio Kelsen se ocupou da experiência suíça de controle federal da legislação cantonal, ou o caso da constituição republicana portuguesa anterior a Weimar. Rafael Bielsa, na Argentina de 1935, escrevia a primeira edição de "La protección constitucional y el recurso extraordinário", com uma segunda edição em 1958. Já em 1915, em Montevidéu, conhecia-se o trabalho de Jiménez de Aréchaga denominado Sobre la inaplicabilidad de leyes inconstitucionales. Também se encontra o texto do mexicano Rodolfo Reyes ${ }^{38}$ (1934) tão admirado na Espanha por seu trabalho em torno à ação de amparo, que se agrega a uma série de escritos que destacam este aludido ${ }^{39}$ instrumento e que deram lugar à subdisciplina - com um bom sabor mexicano - do direito processual constitucional, com uma série de trabalhos que se remontam anteriores aos textos kelsenianos e que influenciam, inclusive para outros lados do Atlântico, como reconhecido por Cappelletti. ${ }^{40}$

$\mathrm{Na}$ Colômbia, circulou uma importante bibliografia que defendia e elogiava a ação pública de inexequibilidade, ${ }^{41}$ ao mesmo tempo em que

38 REYES, Rodolfo. La defensa constitucional. Madrid: Espasa - Calpe, 1934.

39 VALLARTA, Ignacio Luis. El juicio de amparo y el Writ of Habeas Corpus. México: edición arreglada por el lic. Alejandro Vallarta, 1896.

40 CAPPELLETTI, Mauro. Obras: la justicia constitucional y dimensiones de la justicia en el mundo contemporáneo. Prólogo de Héctor Fix Zamudio. Presentación de Fernando Serrano Migallón. México: Porrúa y UNAM, 2007, p. 3-351.

41 Por exemplo, RODRÍGUEZ PIÑERES, Eduardo. Relaciones entre los poderes judicial y legislativo. En: RODRÍGUEZ PIÑERES, Eduardo. Por el reinado del derecho: escritos varios. Bogotá: Imprenta de la Luz, 1927, p. 336-337. 
começava a aparecer uma literatura importante em defesa dos sermões kelsenianos contra o neotomismo e o formalismo pseudoexegeta que prevalecia na formação universitária hispano-americana. $\mathrm{Na}$ Espanha, encontra-se Pérez Serrano com "El proyecto de tribunal de garantias y el recurso de inconstitucionalidad" de 1933, assim como "La constitución española editada", em 1932; Fernández de Velazco ("Cuestiones prácticas. El Tribunal de Garantias Constitucionales" de 1933), De Arcaya (com “El Tribunal de Garantías Constitucionales”de 1934), etc. Na Alemanha, estão os trabalhos de Buhler (com uma tradução ao espanhol de Rovira Armengol), ${ }^{42}$ nos quais deve ser destacada sua análise a favor de uma justiça constitucional. Agregue-se que chega à Espanha e Hispano-América uma bibliografia diversa sobre o controle judicial da constituição (sendo interessante a leitura de Holcombe com seu texto "State Government of the United States" - governo estatal dos Estados Unidos -, publicado em Nova Iorque em 1916, e de Jellinek, com sua Teoría del Estado, com tradução de Fernando de los Rios em 1915, entre outros), juntamente aos textos que constituem o debate Kelsen-Schmitt, a finais da década de vinte e princípios da década de trinta (é caso de Sánchez Sarto, que traduz Der Hüter der Verfassung - "O guardião da Constituição" - de C. Schmitt, como "La defensa de la Constitución", em 1931, sendo editado em Barcelona no mesmo ano da publicação do texto kelseniano, “Wer soll der Hüter der Verfassung sein?” - "Quem deve ser o guardião da constituição?"; assim como a grande circulação de "La garantie juridictionnelle de la Constitution" ("a garantia jurisdicional da Constituição") do próprio Kelsen e "Wesen und Entwicklung der Staatsgerichtsbarkeit” ("A natureza e o desenvolvimento da jurisdição do Estado"), ambos de 1928, que complementam as decisões tomadas por ele em 1920 com "Vom Wesen un Wert der Demokratie" ("A essência e o valor da democracia") e que volta a editá-lo pela sua urgência e relevância em 1929), que ajudou a mitigar o olhar que se tecia sobre o Tribunal de Garantias Constitucionais da II República espanhola em 1931. ${ }^{43}$ Ademais,

42 BUHLER, Ottmar. La Constitución alemana. Trad. de Rovira Armengol. Barcelona: Labor, 1931.

43 FERNÁNDEZ SEGADO, Francisco. La jurisdicción constitucional en España. Bogotá: Universidad Externado de Colombia, 1999, p. 9-10. CRUZ VILLALÓN, Pedro. 
se está em um período de reivindicação judicial diante da crise do código, que caía em defesa de um modelo de judicial review, o que explica em certa medida o sucesso da recepção de Geny e a literatura emergente sobre a jurisdição constitucional (para a Colômbia, por exemplo, o texto de Araújo "Jurisdicción constitucional” de 1936).

Poder-se-ia muito bem continuar citando a recepção de textos concomitantes (e provavelmente um pouco influenciados por Kelsen), mas que dão a ideia exata de que não se tratou de um concerto solista do austríaco, mas de uma orquestra inteira retumbando (pelo menos) na Península Ibérica e na Hispano-América. Isto, por sinal, de algum modo justifica a pertinência de uma mudança de rumo na história do Direito, no sentido de resgatar os estudos de culturas jurídicas, mais do que os "grande autores", posto que estes últimos obtêm tais qualificativos e proeminências no contexto de culturas jurídicas que lhes justificam e explicam.

\section{Conclusão}

Com este trabalho pretende-se deixar claro que o "decisionismo" judicial estadunidense e o constitucionalismo europeu do pós-guerra, pelo menos para a América Latina, não são as únicas referências, e que não estamos diante de um transplante passivo de duas tradições jurídicas "maiores"; e que tampouco pode-se levar a crer que não haja nada de novo sob o sol ou, pior ainda, que todo o contemporâneo já estivesse de forma idêntica no passado. Este último seria um anacronismo cruel, que não raro se camufla, (impunemente) em vários textos dogmáticos com o apelido de "antecedentes". Por fim, que existe algo em nossa cultura jurídica latino-americana que merece ser "historizado" e não simplesmente "invisibilizado" pelo discurso colonialista que, constantemente, paira sobre o mundo acadêmico.

Em suma, há uma reflexão crítica em mente, como uma obsessão: o problema que vários dogmáticos e historiadores do Direito ignorem os discursos jurídicos pretéritos em suas matérias e suas regiões, e tomem

La formación del sistema europeo de control de constitucionalidad (1918-1939). Madrid: Centro de Estudios Constitucionales, 1987, p. 309-317. 
como dogmas as afirmações repetidas à exaustão nas escolas jurídicas, recebidas de autores forâneos da moda, que, seguramente, satisfazem as suas próprias tradições jurídicas. Isto levou, infelizmente, à perda de uma memória valiosa no (dogmático e historiador do direito) constitucionalista de muitos temas próprios da interpretação constitucional ibero-americana, e a valorizar apenas a memória forânea que se transmite em exercícios acadêmicos que reproduzem lógicas coloniais. Por este esquecimento, que pode ser consciente ou não, foi perdida a capacidade de se seguir sobre aquilo que merece, e a cultura acadêmica se inclina em contínuas "descontinuidades"; isto é, em aceitar constantemente como próprias as rupturas epistemológicas forâneas, ridicularizando e "invisibilizando" o existente, que, por sua vez, era fruto, entre outras coisas, de imposições culturais anteriores processos de recepção criativa. É exatamente isto que acontece quando, em nossa cultura jurídica, aparecem agentes discursivos que, tomando a ruptura epistemológico-constitucional europeia do pós-guerra, acreditam e fazem os outros crer que o passado europeu foi, igualmente, o mesmo passado latino-americano e que, portanto, as distinções e as conclusões que os constitucionalistas europeus possam fazer sobre as suas constituições do século XIX se estenderiam, através dessas leituras receptoras que foram anteriormente referidas, às constituições latino-americanas do mesmo período.

No entanto, o quadro é muito mais complexo do se pode crer, porque o discurso jurídico hegemônico busca que certa ideia, norma ou instituição seja imposta a uma cultura jurídica preexistente, utilizandose, para isto, da atitude acrítica e com poucos matizes de uma cultura acadêmica latino-americana propensa a idolatrar o forâneo, ainda que o existente neste momento de imposição fosse, por sua vez, uma mistura de elementos jurídicos igualmente impostos, mas com variáveis diferentes, e de outros exercícios neocoloniais anteriores que se somaram com elementos "próprios" (e, por sua vez, estes elementos "próprios" foram também a confluência em tempos anteriores de recepções de posturas forâneas junto com elementos próprios). Isto nos leva a considerar seriamente a existência de uma contínua recepção criativa que faz com que o efeito deste processo - ou melhor, o que ficou como "recebido e/ou copiado" - seja parcialmente diferente da causa - isto é, o "enviado e/ou tomado" -, processo que imprime uma certa identidade interna e externamente ao sistema. 
Tudo isto torna difícil, então, partir de um dualismo "próprio" "forâneo", que, embora de fácil memorização acrítica e, portanto, de se reproduzir como um dogma, é tão falsa como as dualidades que têm sido criticadas aqui antes, neste artigo. Por exemplo, o fato de se reconhecer que existiram exercícios de aplicação judicial da constituição no século XIX, não significa que esta aplicação judicial tenha sido um elemento "originário" ou "próprio" diante da ideia forânea, hoje em dia tomada por muitos como verdade, que o século XIX latino-americano tenha sido um século sem judicial review (que seria a ideia "forânea"), uma vez que esta aplicação judicial foi, entre outras coisas, resultado de outros processos colonizadores (na região ou fora dela), em seu momento. Considerese, no caso do Sr. Cruz, como o juiz de Direito se impôs, com lógicas jurídicas desconhecidas, a um prefeito que estava fazendo aquilo que vinha sendo feito desde algum tempo na sua comunidade: não se trata de outro exercício hegemônico?

Agora, reconhecer a existência de uma contínua história das descontinuidades pelos exercícios colonizadores não leva, necessariamente, a juízos morais e políticos predeterminados. Eles são bons ou maus? São certos ou errados? São pertinentes ou inoportunos? No seu caso, poderá julgar-se, a partir dos estereótipos de quem julga e com a suposição ideológica de um auditório que acredita que se poderá convencer. Mas, no final, uma coisa não leva à outra.

Então, este sistema é mais complexo do que parece, uma vez que o exercício neocolonial no pensamento jurídico não é novo, o que faz com que o historiador do Direito encontre como "próprio" os implantes de raciocínio jurídico que, da mesma forma, inviabilizaram outras linhas de pensamento no passado. Assim, tanto o historiador do direito colonizado (consciente ou inconscientemente), como um crítico que faz matizes (que ainda assim não poderá chegar a uma posição originária, isto é, isenta de qualquer exercício neocolonial) encontrarão informações a seu favor em um passado que, por desacreditado, está quase todo por explorar. Desta forma, não faltarão, nessas complexas idas e vindas do pensamento jurídico, traços de experiência constitucional "própria", bem como de implantes que se fundiram com essa experiência, resultando na impossibilidade de declarar no mundo da vida, como mencionado, as 
dualidades irredutíveis "próprio" (ou "nacional") - "forâneo", o que exige novas formas de investigar. Somente assim, afastando-se tanto quanto possível das dicotomias, especialmente se são irredutíveis, e buscando a continuidade dialética com a própria tradição - se poderá conceber um modelo sustentável de diálogo acadêmico produtivo ao interior da história do Direito entre as diferentes "memórias" do que foi jurídico em diversos espaços-tempo vitais, posto que na subordinação não há possibilidade de diálogo. Em outras palavras, não se propõe uma ruptura do diálogo com outras tradições, se não, canalizar as possíveis relações entre elas, do plano da hegemonia ao plano do diálogo, assunto que, ademais, poderá conduzir de melhor forma a uma história do Direito fundada nas comparações não reducionistas e nas conexões.

Além disso, a relação hegemônica não é tão simples como uma oposição colonial norte - sul, como os hemisférios. Acontece que essas relações hegemônicas também se apresentaram e se apresentam, paralelamente, no próprio interior dos hemisférios, podendo ser historizadas como o "centro" (que, repita-se, tanto pode ser externo como interno) impõe-se sobre a "periferia", sendo, perfeitamente, o centro, alguns espaços-tempo privilegiados no raciocínio jurídico que, por sua alta carga energética, pode se impor, amoldando, ainda que nem sempre aniquilando a experiência jurídica do colonizado. Um exemplo disso é ver como algumas escolas jurídicas são capazes de impor modelos de sujeição no pensamento jurídico sobre outras, dentro de uma mesma região ou, no caso de Cruz, os juízes de Direito sobre os prefeitos ordinários, o que mostra a complexidade do fenômeno que aqui se demonstra, mas que, por mais complexo, não reduz o valor do afirmado em torno da importância de reconhecer que, desde muito antes do que se quis acreditar, na América Latina já havia exercícios diferentes aos dos europeus sobre a vivência da constituição. Esperemos que não seja necessário lembrar à próxima geração de juristas constitucionalistas latino-americanos, diante dos ataques colonizadores a que estão e estarão submetidos, que houve um passado (mestiço, se assim se prefere) regional nas instituições que se considerará uma herança de "culturas jurídicas maiores".

Em outras palavras, se se trata de interpretar a constituição, esta tem sido interpretada na Ibero-América muito antes do que quer a nova 
epistemologia colonial aceitar, pelo menos, para seus territórios. Outra coisa que se quer é qual a forma de interpretá-la corresponda ao modelo que hoje em dia se erige como paradigma a se seguir.

Mas, para reformular essas relações hegemônicas dentro da dogmática constitucional, é preciso revitalizar a história do Direito, aproveitando o impulso que esta tem obtido pela ocasião do bicentenário. Uma história do Direito, entendida como disciplina jurídica, com a missão de formar a memória do jurista e do jurídico, ${ }^{44}$ dialogando com a dogmática, fornecerá contextos claros para que essas relações de colonialismo cultural possam ser postas sob suspeita, como aqui se pretende.

\section{Referências}

ABREU Y ABREU, Juan Carlos. La justicia constitucional a dos fuegos: federalistas contra centralistas. In: Suprema Corte de Justicia de la Nación. Historia de la Justicia en México, siglos XIX y XX. Tomo I. México: Suprema Corte de Justicia de la Nación, 2005. p. 3-21.

AGUILÓ REGLA, Josep. Cuatro pares de concepciones opuestas de la Constitución. In: AGUILÓ REGLA, Josep; ATIENZA, Manuel; RUIZ MANERO, Juan. Fragmentos para una teoría de la constitución. Madrid: Iustel, 2007. p. 21-62.

AGUILÓ REGLA, Josep. Sobre derecho y argumentación. Palma de Mallorca: Lleonard Muntaner, 2009.

AGUILÓ REGLA, Josep. Sobre la constitución del estado constitucional. In: Doxa, n. 24, 2001, p. 429-457.

AHUMADA RUÍZ, María Ángeles. Marbury Versus Madison, Doscientos años (y más) después. In: Fundamentos, n. 4, 2006.

ALEXY, Robert. El concepto y la validez del derecho. Trad. Jorge M. Seña. Barcelona: Gedisa, 1994.

44 PETIT, De la historia a la memória, op. cit. . 
AYALA CORAO, Carlos M. La jurisdicción constitucional en Venezuela. In: GARCÍA BELAUNDE, D.; FERNÁNDEZ SEGADO, F. (Coord.). La jurisdicción constitucional en Iberoamérica. Madrid: Dykinson, 1997. p. 933-936.

AYALA CORAO, Carlos M. Origen y evolución del control constitucional en Venezuela. In: AA.VV. Anuario de derecho constitucional latinoamericano. Medellín: Fundación Konrad Adenauer, CIEDLA, Asociación Venezolana de derecho constitucional, Asociación costarricense de derecho constitucional y Diké, 1996. p. 247-284.

BOTERO BERNAL, Andrés. Haciendo memoria de la defensa judicial de la Constitución. In: Pensamiento Jurídico: Universidad Nacional de Colombia, n. 20, septiembre/diciembre de 2007, p. 91-101.

BREWER-CARÍAS, Allan R. El sistema mixto o integral de control de constitucionalidad en Colombia y Venezuela. In: AA.VV. Anuario de derecho constitucional latinoamericano. Medellín: Fundación Konrad Adenauer, CIEDLA, Asociación Venezolana de derecho constitucional, Asociación costarricense de derecho constitucional y Diké, 1996. p. 163-243.

BREWER-CARÍAS, Allan R. La jurisdicción constitucional en América Latina. In: GARCÍA BELAUNDE, D.; FERNÁNDEZ SEGADO, F. (Coord.). La jurisdicción constitucional en Iberoamérica. Madrid: Dykinson, 1997. p. 125-135.

BUHLER, Ottmar. La Constitución alemana. Trad. de Rovira Armengol. Barcelona: Labor, 1931.

CAPPELLETTI, Mauro. Obras: la justicia constitucional y dimensiones de la justicia en el mundo contemporáneo. México: Porrúa y UNAM, 2007.

CID SEBASTIÁN, Elia. Antecedentes del juicio de amparo. De la Real Audiencia a la Suprema Corte de Justicia de la Nación. In: Suprema Corte de Justicia de la Nación. Historia de la Justicia en México, siglos $X I X$ y XX. Tomo I. México: Suprema Corte de Justicia de la Nación, 2005. p. 89-116.

CONSTANT, Benjamin. Curso de política constitucional. Trad. D. J. C. Pages. Paris: Librería de Rosa, 1825. Tomo II. 
COUTURE, Eduardo J. Estudios de derecho procesal civil. Tomo I: La Constitución y el proceso civil. 2. ed. Buenos Aires: Depalma, 1978.

CRUZ VILLALÓN, Pedro. La formación del sistema europeo de control de constitucionalidad (1918-1939). Madrid: Centro de Estudios Constitucionales, 1987.

DIETZE, Gottfried. Judicial review in Europe. In: Michigan Law Review, v. 55, February 1957, n. 4.

EDER, Phanor J. Judicial review in Latin American. In: Ohio State Law Journal, 1960, p. 570-615.

FERNÁNDEZ SEGADO, Francisco. Evolución histórica y modelos de control de constitucionalidad. In: GARCÍA BELAUNDE, D.; FERNÁNDEZ SEGADO, F. (Coord.). La jurisdicción constitucional en Iberoamérica. Madrid: Dykinson, 1997.

FERNÁNDEZ SEGADO, Francisco. La jurisdicción constitucional en España. Bogotá: Universidad Externado de Colombia, 1999.

FIX-ZAMUDIO, Héctor; VALENCIA CARMONA, Salvador. Derecho constitucional mexicano y comparado. México: Porrúa y UNAM, 1999.

FRICKEY, Philip P. (Native)American Exceptionalism in Federal Public Law. In: Harvard Law Review, v. 199, December 2005, n. 2, p. 431-490.

GARCÍA PASCUAL, Cristina. Legitimidad democrática y poder judicial. Valencia: Edicions Alfons el Magnánim, 1997.

LORENTE SARIÑENA, Marta. Las infracciones a la Constitución de 1812. Madrid: Centro de Estudios Constitucionales, 1988.

MONTERO AROCA, Juan. La Ley de enjuiciamiento civil española de 1855: la consolidación del proceso común. In: GIULIANI, Alessandro; PICARDI, Nicola. L'Educazione giuridica. VI - Modelli storici Della procedura continentale. Tomo II - Dall'ordo iudiciarius al codice di procedura. Napoli: Edizioni Scientifiche Italiane, 1994. p. 347-458.

MUÑOZ, Francisco de Paula. El Crimen del Aguacatal. Medellín: Imprenta del Estado por León F. Villaveces, 1874. 
NARVÁEZ HERNÁNDEZ, José Ramón. Historia social de la defensa de los derechos en México: El origen del juicio de amparo en la península yucateca. México: Suprema Corte de Justicia de la Nación, 2007.

PEREIRA MENAUT, Antonio Carlos. Lecciones de teoría constitucional. 2. ed. Madrid: Editorial Revista de Derecho Privado, 1987. p. 245-246.

PETIT, Carlos. De la historia a la memoria. A propósito de una reciente obra de historia universitaria. In: Cuadernos del Instituto Antonio de Nebrija de Estudios sobre la Universidad, n. 8 (2005), p. 237-279.

PRAKASH, Saikrishna. New Light on the decision of 1789. In: Cornell Law Review, v. 91, July 2006, n. 5, p. 1022-1023.

RESTREPO PIEDRAHITA, Carlos (Comp.). Control de constitucionalidad: Colombia y República de Nueva Granada, 18211860. Bogotá: Universidad Externado de Colombia, 2006.

REYES, Rodolfo. La defensa constitucional. Madrid: Espasa - Calpe, 1934.

SCHWARTZ, Bernard. A history of the Supreme Court. New York/ Oxford: Oxford University Press, 1993. p. 105-125.

RODRÍGUEZ PIÑERES, Eduardo. Relaciones entre los poderes judicial y legislativo. In: RODRÍGUEZ PIÑERES, Eduardo. Por el reinado del derecho: escritos varios. Bogotá: Imprenta de la Luz, 1927. p. 336-337.

SOBERANES, José Luis. Notas acerca del control de la constitucionalidad de las leyes. In: Estudios jurídicos en homenaje al profesor Santa Cruz Teijeiro. Valencia: Universidad de Valencia, 1974. Tomo 2, p. 420-421.

TAPIA, Eugenio de. Febrero novísimo, ó librería de jueces, abogados y escribanos, refundida, ordenada bajo nuevo método, y adicionada con un tratado del juicio criminal, y algunos otros. Valencia: Imprenta de Ildefonso Mompié, 1828. Tomo I.

TREANOR, William Michael. Judicial review before Marbury. In:

Stanford Law Review, v. 58, n. 2, November 2005, p. 455-562. 
URIBE VARGAS, Diego. Las constituciones de Colombia. Tomo I y II. Madrid: Ediciones Cultura Hispánica, 1977.

VALLARTA, Ignacio Luis. El juicio de amparo y el Writ of Habeas Corpus. México: edición arreglada por el lic. Alejandro Vallarta, 1896.

VERDÚ, Pablo Lucas. Tener y estar en Constitución. In: Anales de la Real Academia de Ciencias Morales y Políticas, n. 85 (2008), p. 322-334.

WATSON, Alan. Legal transplants: An approach to comparative law. Edinburgh: Scottish Acad. Press, 1974.

ZAGREBELSKY, Gustavo. El derecho dúctil: ley, derechos, justicia. Trad. Marina Gascón. Madrid: Trotta, 1999. p. 109-130. 